\title{
Poder e política na teoria sociológica contemporânea: a abordagem dos estudos de governamentalidade
}

\author{
Fernando Cardoso Lima Neto ${ }^{1}$
}

Resumo: Parto da relação entre teoria sociológica e história para introduzir o debate sobre os estudos de governamentalidade dentro de questões contemporâneas sobre política e poder. Começo por expor uma visão geral sobre o conceito de governamentalidade na obra de Michel Foucault. Em seguida, apresento separadamente a reapropriação deste conceito feita por dois autores contemporâneos, Nikolas Rose e Aihwa Ong. Feito isso, proponho uma aproximação entre esses autores, buscando explicitar os critérios teóricos e metodológicos que validam essas diferentes abordagens como constitutivas de um mesmo campo de investigação. Na última seção, apresento alguns apontamentos conclusivos na medida em que procuro contrabalancear avanços e limitações dos estudos de governamentalidade no enfrentamento de questões sociológicas contemporâneas.

Palavras-chave: estudos de governamentalidade; poder; política; teoria sociológica contemporânea.

Power and politics in the contemporary sociological theory: the approach of the studies of governmentality

\begin{abstract}
Beginning of the relation between sociological theory and history to introduce the debate on governmentality's studies of contemporaries questions on politics and power. I start displaying a general vision on the concept of governmentality in the workmanship of Michel Foucault. After that, I present separately a reappropriation of this concept made for two authors contemporaries, Nikolas Rose and Aihwa Ong. Made this, I consider an approach between these authors, searching to contrabalance the theoretical and metodological criteria that validate these different boardings as constituent of one same field of inquiry. In the last section, I present some conclusive notes in the measure where I look for to contrabalance advances and limitations of the studies of governmentality in the confrontation of sociological questions contemporaries.
\end{abstract}

Key-words: studies of governmentality; power; politics; sociological theory contemporary.

\footnotetext{
${ }^{1}$ Mestre em Sociologia e Antropologia e doutorando em Sociologia no Programa de PósGraduação em Sociologia e Antropologia do Instituto de Filosofia e Ciências Sociais da Universidade Federal do Rio de Janeiro, E-Mail: fercaline@ gmail.com
} 


\section{Teoria e história na produção de conhecimento sociológico}

Em meio à tendência geral revisionista que vem marcando parte significativa dos estudos sociológicos na contemporaneidade, muita atenção é conferida ao esgotamento heurístico de algumas categorias analíticas que foram fundamentais para a própria legitimação da sociologia. O conceito de "nação" tem catalisado boa parte desses estudos críticos e, hoje, já se convencionou chamar de "nacionalismo metodológico" as investidas que tendem a fazer deste conceito o principal ponto de partida e/ou chegada na abordagem sociológica. A característica fundamental que permeia o assim chamado nacionalismo metodológico consiste em equacionar Estado-nação e sociedade (CHERNILO, 2006; BECK, 2000; SMITH, 2000; REIS, 1998; TOURAINE, 1984). A sociedade nacional fora pensada como um corpo uniforme cujas fronteiras estavam bem delineadas dentro de um Estado centralizado. Grande parte dos modelos convencionais de análise sobre política e poder na sociologia ao longo do século XX estão diretamente associados a esta tradição. Em um mundo onde a geopolítica parecia ser inevitavelmente conduzida em termos de alianças e conflitos entre Estados nacionais, teoria sociológica e história se confundiam nas reflexões sobre o lugar e o papel do Estado na ordenação política da vida em sociedade.

De fato, é difícil imaginar se isso poderia ser diferente. Os inputs gerados pelo conhecimento sociológico estão na contrapartida inerente da geração contínua de auto-conhecimento na vida social. Teoria sociológica e história estão intimamente relacionadas no fazer reflexivo da sociologia. A produção teórica sociológica envolve duas dimensões que são, ao mesmo tempo, independentes e correlacionadas. Por um lado, há a construção de proposições gerais que definem a demarcação de temas, paradigmas, teorias e métodos específicos a estas disciplinas, isto é, o exercício lógico-analítico que define a abordagem sociológica como tal. Por outro lado, essas proposições estão diretamente condicionadas a constrangimentos históricos; tanto no que diz respeito ao fato elementar de que a construção dos seus objetos possui referência constante a fenômenos históricos, quanto ao fato hermenêutico de que o arcabouço analítico dessas disciplinas é continuamente alimentado e reajustado pela história do presente, isto é, pelo próprio tempo histórico em que vivem seus autores. A consagração do vínculo congênito entre sociedades nacionais, modernidade e sociologia é um exemplo bastante significativo desta correlação entre teoria sociológica e história, e até bem pouco tempo coordenou praticamente todos os avanços desta disciplina.

Nas últimas décadas, contudo, novos exemplos de correlação entre teoria e história têm alterado radicalmente os esquemas conceituais mais convencionais da sociologia. A intensificação dos vários fenômenos globais que têm redimensionado o lugar e as fronteiras do Estado nacional vem exigindo uma revisão críticas dos instrumentais teóricos da disciplina, até então formulados em meio à centralidade conceitual do Estado nação. Hoje em dia, muito se tem falado sobre mudanças nas organizações das relações sociais e sobre as dificuldades da sociologia em explicá-

Latitude, Vol. 1, nํ2, pp.80-98, 2007. 
las. De fato, parece haver um mal-estar generalizado entre os sociólogos contemporâneos, que assistem e experimentam transformações históricas evidentes sem conseguir formular hipóteses seguras de explicação sobre elas. Se, por um lado, estabelece-se algum nível de concordância mais geral no reconhecimento de que o Estado nacional não deva mais ser necessariamente o conceito central na proposição e investigação de questões sociológicas, por outro, parece que ainda não há indícios mais seguros de consenso em relação ao modo como deva proceder a sociologia no enfrentamento destas questões.

Contudo, seria equivocado afirmar que os sociólogos não têm se esforçado para dar conta dessas transformações, ou que o tratamento dos problemas contemporâneos na sociologia esteja sendo levado em um vácuo teórico. Aqui e ali começam a brotar propostas sugestivas de compreensão e explicação dos fenômenos históricos contemporâneos, o que acaba por favorecer a criação, ainda que incipiente, de novos modelos de solidariedade intelectual entre autores dedicados a analisar fenômenos contemporâneos. Vejamos aqui, em linhas breves e gerais, um dos novos caminhos que se abrem à sociologia no enfrentamento destas questões. Nas seções que seguem irei apresentar um novo campo de investigações sobre política e poder dentro das ciências sociais: os estudos de governamentalidade. Esses estudos, que têm ganhado gradativa relevância no cenário contemporâneo da sociologia, retomam a noção foucaultiana de "governamentalidade" e procuram propor novos modelos analíticos, diferentes daqueles consagrados pelo nacionalismo metodológico.

$\mathrm{Na}$ próxima seção, exponho uma visão geral sobre o conceito de governamentalidade dentro da obra de Michel Foucault. Parto da correlação entre conhecimento e poder para introduzir a noção de governamentalidade como um novo paradigma de concepção sobre poder. Nas duas seções seguintes, trato da contribuição do sociólogo contemporâneo Nikolas Rose. Primeiramente, destaco o realinhamento das noções de Estado e governo dentro do aparato conceitual desta abordagem para, em seguida, enfatizar alguns de seus aspetos metodológicos. $\mathrm{Na}$ quarta seção exponho a contribuição da antropóloga Aihwa Ong, que se dedica a explorar os efeitos particulares que a formação discursiva sobre o neoliberalismo tem provocado em diferentes regiões do mundo. Depois disso, proponho uma aproximação entre esses autores, buscando explicitar os critérios teóricos e metodológicos que validam essas diferentes abordagens como constitutivas de um mesmo campo de investigação, os estudos de governamentalidade. A sexta e última seção é reservada para apontamentos conclusivos. Procuro contrabalancear avanços e limitações destas abordagens no enfrentamento de questões sociológicas contemporâneas. Se, por um lado, avançam na intenção de fundar um campo de investigação sobre a produção de verdades em suas relações de poder, por outro, retrocedem quando condicionam a investigação ao abandono de pretensões de generalização teórica. 


\section{A história em rupturas: poder e conhecimento na abordagem foucaultiana}

Um tema permanente em todos os trabalhos de Michel Foucault é a relação entre poder e saber, aquilo que ele entende como "produção de verdades". Para Foucault, as produções de verdades não podem ser dissociadas do poder e de seus mecanismos (suas técnicas e métodos de execução). Por um lado, são os mecanismos de poder e as formas de saber que lhes são associadas o que torna possível a criação de verdades. Por outro lado, a consagração de verdades possui um efeito direto sobre esses mesmos mecanismos de poder e formas de saber. Para compreender essa implicação mútua entre conhecimento e poder, Foucault procurou compreender as relações microscópicas que estão subjacentes às grandes estruturas do poder. Qualquer relação de poder só é possível se for amparada por métodos e técnicas que são diferentes entre si, segundo as épocas e os níveis de sua aplicação. Foucault procura identificar inflações de poder que estão presentes na vida cotidiana: nas relações entre os sexos, nas famílias, entre doentes mentais e pessoas sensatas, entre doentes e médicos, médicos e juízes, etc. Entende que o poder é algo coextensivo ao corpo social, e não o resultado da emanação de uma fonte única, seja ela o Estado ou seja qualquer outra grande estrutura (FOUCAULT, 2003, pp. 223-252). Para Foucault, a produção das verdades que regem a vida em sociedade só é possível mediante o exercício de um poder microscópico, capilar, que define tipos específicos de subjetividades e de formas de saber. Neste sentido, a produção de verdades não pode ser dissociada dos fundos de saber que são por eles criados nas sociedades. A formulação das verdades que organizam a vida social não é o produto deliberado de ações intencionais de indivíduos isolados, nem de coerções supra-individuais de grandes estruturas trans-históricas. Antes, a formulação de verdades diz respeito ao enquadramento lógico de modelos heterogêneos de racionalidade que fabricam suas próprias regras. Em uma frase, as verdades são enunciados discursivos.

Foucault chama de "prática discursiva" o conjunto de regras que são anônimas, históricas, sempre orientadas no tempo e no espaço, e que definem, em uma dada época e para uma determinada área social, econômica, geográfica ou lingüística, as condições de exercício da sua função enunciativa². Para Foucault, o

2 Foucault insiste que é na irrupção dos acontecimentos que estão determinadas as condições de existência dos discursos, e não em regras pré-definidas.Ao invés de se preocupar com regras gerais que supostamente constroem os enunciados, o autor foca atenção na descrição dos acontecimentos que desencadeiam o aparecimento de um enunciado específico em detrimento de outros, já que, inspirado em Nietzsche, considera os enunciados como vontades de potência, fatores em constante conflito. A análise do campo discursivo, portanto, se dá a partir da compreensão dos enunciados na estreiteza e singularidade da sua situação, devendo ser exposto as razões pelas quais comparece um e não outro enunciado, isto é, a posição que este enunciado ocupa em relação a outros, o porquê dele ocupar um lugar que nenhum outro poderia ocupar (FOUCAULT, 2000).

Latitude, Vol. 1, nำ, pp.80-98, 2007. 
discurso é algo histórico em sua descontinuidade. $\mathrm{O}$ autor não tem por objetivo nem tratar de um princípio explicativo sobre a seqüência singular de eventos que caracterizam um fenômeno histórico particular, nem tratar de teorias gerais sobre fenômenos que acontecem na história. Neste sentido, sua abordagem histórica é diferente tanto do trabalho de historiadores quanto de sociólogos. Foucault está interessado em produções de verdades que são históricas sem serem redutíveis à história e que são gerais sem serem redutíveis a um enunciado teórico genérico e probabilístico. Ao compreender a produção de verdades como um fenômeno de ordem eminentemente discursiva, Foucault recorre à abordagem histórica sem conferir destaque nem aos atores individuais nem às coerções sociais. Antes, ressalta as coerções internas que são específicas a cada um dos enunciados discursivos. Para Foucault, compreender os discursos através de suas próprias regras de formação é "caracterizar um discurso ou um grupo de enunciados pela regularidade de uma prática" (FOUCAULT, 2000, pp. 40 e 82). Entende que "verdade" não é uma espécie de norma geral, mas um "conjunto de procedimentos que permitem a cada instante e a cada um pronunciar enunciados que são considerados verdadeiros" (FOUCAULT, 2003, p. 233).

A genealogia do poder, isto é, a descrição microscópica dos mecanismos que engendram as suas relações, não tem por objetivo tratar de verdades ontológicas. Antes, este exercício analítico procura identificar o tipo de cálculo, a ratio que confere legitimidade a determinados discursos, proposições de verdade (ib. p. 327). Neste sentido, se não é propriamente uma teoria geral, não é também uma história das idéias o objetivo do trabalho de Foucault. $\mathrm{O}$ autor não procura reconstituir o passado em si mesmo, mas sim as suas lógicas, isto é, os modelos de racionalidade que legitimam determinadas relações mutáveis entre conhecimento e poder. Ao propósito de compreender de que modo foi possível o aparecimento de certas formas de saber relacionadas com determinadas práticas sociais, Foucault expõe um modo criativo e particular de apreensão da história. Refuta o entendimento da história como uma seqüência de fatos linearmente dispostos e experimentados por um sujeito do conhecimento apto a avaliá-los, para afirmar a história em suas rupturas. Para Foucault, as práticas sociais, em suas realizações de poder, engendram domínios de saber que geram não apenas novos objetos e conceitos, mas também fazem nascer formas totalmente novas de sujeitos e de sujeitos de conhecimento.

Neste sentido, por exemplo, o autor se propõe a demonstrar como foi possível a formação, no século XIX, de uma concepção de sujeito intimamente ligada a práticas sociais de controle e vigilância característica das modernas sociedades ocidentais (FOUCAULT, 1987 e 1996). Diferentemente da "arte de punir", que estabelecia uma correspondência cuidadosa entre natureza do delito e forma da pena, o século XIX viu nascer um novo sistema punitivo, mais uniforme: o encarceramento. De modo semelhante, em outros trabalhos Foucault procura no intervalo entre os séculos XVI e XVIII a emergência de um saber específico sobre o governo de populações através dos mecanismos que, hoje, conhecemos como "economia política". A soberania do príncipe, que vigorou absoluta até meados do século XVI, gradativamente cedeu lugar a uma concepção descentrada de governo, 
cuja finalidade estava menos ligada à obediência incondicional do principado e mais relacionada à gestão eficiente de recursos humanos e não humanos na realização de objetivos específicos. Em ambos os casos, Foucault observou o desenvolvimento de formações discursivas que tiveram origem na história e que remodelaram tanto práticas de punição quanto práticas de governo nas modernas sociedades ocidentais. Nos parágrafos seguintes, tomarei o segundo exemplo (sobre governo) para demonstrar como Foucault procede este tipo particular de análise histórica.

Desde a Antiguidade, sempre existiram tratados políticos que visavam oferecer "conselhos" aos soberanos para que esses exercessem e conduzissem o poder de uma forma absoluta sobre os seus súditos. "O Príncipe", de Maquiavel (1532), é o exemplo mais emblemático e mais conhecido desses tratados. No entanto, Foucault observa que a partir do século XVI começaram a aparecer novos modelos de tratados políticos, que não tinham mais por objetivo aconselhar o exercício da soberania absoluta a uma autoridade até então percebida como única fonte de poder. Ao invés disso, esses novos tratados políticos eram apresentados como "artes de governar", enfatizando-se uma pluralidade de formas de governos, que eram exercidos em várias dimensões da vida social, algo que se opunha radicalmente à singularidade transcendente do Príncipe de Maquiavel. Mais do que habilidade para conservar um principado, passava-se a exigir dos governantes o reconhecimento de novas modalidades de governo interiores ao próprio Estado. Exigia-se dos governantes a capacidade para coordenarem o bom funcionamento de formas de autoridade que estariam mais distantes do exercício direto da soberania estatal, ou seja, esses novos textos enfatizavam diversas outras formas de governo, como aquele exercido por um pai de família que governa sua própria família, pelo superior de um convento que governa o seu próprio convento, pelo professor que governa seus alunos, etc. Foucault observou que começava a surgir na segunda metade do século XVI um novo conjunto de formações discursivas sobre o que seria um bom governo, formações essas que iriam alcançar o seu ápice no século XVIII, e que transformariam os modos convencionais de se pensar o problema do governo (FOUCAULT, 2003).

Enquanto a doutrina do príncipe procurava incessantemente marcar uma descontinuidade entre o poder do soberano e outras formas de poder, as teorias da arte de governar procuravam estabelecer uma continuidade entre eles. Uma continuidade ascendente no sentido de que aquele que pretende governar um Estado deve antes saber governar a si mesmo, a sua família, os seus bens e seus domínios. Uma continuidade também descendente no sentido de que, quando o Estado é bem governado, os pais de famílias sabem governar suas famílias, suas riquezas, seus bens, e os indivíduos também se comportam como devem (ib. pp. 287-288). No geral, essas novas concepções de governo procuraram introduzir uma maneira eficiente de gestão estatal dos indivíduos, dos seus bens e riquezas, tal como se pode fazer no interior de uma família. Para Foucault, esse movimento resultou na introdução da economia no interior do exercício político, inaugurando um novo campo de intervenção política. A partir disso, o poder político não era mais direcionado apenas para a manutenção de um território e da obediência 
daqueles que nele habitavam. Mais do que ao território e à obediência incondicional de seus habitantes, o governo era direcionado para a gestão de um conjunto de homens e coisas:

Quer dizer que essas coisas das quais o governo deve encarregar-se são os homens, mas em suas relações, seus laços, seus emaranhamentos com essas coisas que são as riquezas, os recursos, as substâncias, o território, com certeza, em suas fronteiras, com suas qualidades, seu clima, sua aridez, sua fertilidade; são os homens em suas relações com outras coisas ainda, que podem ser os acidentes ou as desgraças, as epidemias, a morte (ib. p. 290).

$\mathrm{Na}$ Ideologia que precedeu e coroou Maquiavel, a finalidade maior da soberania não era nada mais do que a obediência absoluta (um fim em si mesmo). Já nos tratados sobre a arte de governar, a finalidade da soberania foi definida em função da correta disposição das coisas das quais se toma o encargo de conduzi-las até um fim conveniente. Deste modo, ao invés de um fim único (entendido geralmente como "bem comum"), destacava-se agora uma pluralidade de fins específicos, que isolavam e resolviam problemas específicos das populações (ib. pp. 299-300). Para isso, foi sendo criada uma série de técnicas de governo (como, por exemplo, a estatística) que permitiram a sistematização e o cálculo de problemas do governo fora do quadro jurídico da soberania. Para Foucault, a constituição de um saber de governo é absolutamente indissociável da constituição de um saber sobre todos os processos referentes à população em um sentido lato, aquilo viria a ser denominado como "economia política" (ib.). No cume deste processo, a partir do século XVIII, tem origem uma nova ruptura nas formações discursivas sobre governo, que se faz influente até hoje: os tratados sobre as artes de governo cediam agora lugar a uma ciência política, isto é, o regime dominado pela estrutura da soberania cedia lugar a um regime dominado por técnicas de governo:

Em todo caso, o que eu queria mostrar era um laço histórico profundo entre o movimento que faz bascular as constantes da soberania para trás do problema mais importante, agora, das escolhas de governo, o movimento que faz aparecer a população como um dado, como um campo de intervenção, como uma finalidade das técnicas de governo e, em terceiro lugar, o movimento que isola a economia como um domínio específico de realidade e a economia política, ao mesmo tempo como ciência e como técnica de intervenção do governo nesse campo de realidade. São estes três movimento, eu acho: governo, população, economia política, dos quais se devem observar que constituem, a partir do século XVIII, uma série sólida que, ainda hoje, não está dissociada (ib. pp. 302-303).

A partir deste momento tem origem aquilo que Foucault definiu como "governamentalidade". Por governamentalidade o autor entende um conjunto de instituições, cálculos e técnicas que permitem o exercício de uma forma bastante específica e complexa de poder, o "governo do governo" (FOUCAULT, 2003; ROSE, 1999), dando origem ao moderno Estado administrativo. Neste processo, mais importante do que a estatização da sociedade é aquilo que Foucault chamou de "govermentalização do Estado", um fenômeno que permitiu ao Estado 
sobreviver na medida em que propiciou a emergência de técnicas de governo que permitem definir a todo momento o que é e o que não é de competência do Estado (FOUCAULT, 2003, p. 305) Em suma, a passagem da ideologia da soberania absoluta para a arte de governar e desta para a economia política revelou a formação um novo tipo de racionalidade de governo, inspirado em uma modalidade pastoral de poder. Trata-se agora de um poder individualizante, cujo papel é zelar pela vida de todos e de cada um (ib. pp. 356 e 366). Governamentalidade, portanto, envolve considerar vários tipos e níveis de autoridade que, no projeto de governar, se relacionam com os mais variados aspectos da vida social, da atividade econômica e da conduta individual. Vejamos nas seções seguintes de que modo esses apontamentos de Foucault sobre a governamentalidade têm inspirado um conjunto de novas reflexões sobre problemas centrais da sociologia contemporânea. Para isso, mencionarei os trabalhos de Nikolas Rose e Aihwa Ong, dois proponentes do chamado "estudos de governamentalidade", que estão atentos às transformações mais recentes sobre o conceito de Estado no debate sociológico atual.

\section{Poder e descentramento do Estado: a abordagem de Nikolas Rose}

O conceito de governamentalidade desenvolvido por Foucault em seus últimos trabalhos tem sido retomado por muitos cientistas sociais e hoje já se convencionou chamar de estudos de governamentalidade o conjunto de abordagens dedicadas a trabalhar esta noção. O trabalho de Nikolas Rose é uma referência neste novo campo de investigações. Nesta seção, irei expor alguns dos postulados teóricos com que o autor tem trabalhado. Ao procurar estabelecer as diretrizes mais gerais da reflexão sobre poder e política no mundo contemporâneo, Rose desafia as concepções mais tradicionais de análises sobre poder político, que são formuladas através da centralidade conceitual da noção de Estado. O autor está mais interessado em formas de poder político que não são estruturadas em termos do papel hegemônico do Estado. Os sistemas modernos de governo dependem de um conjunto complexo de relações entre autoridades estatais e não estatais, e essas relações envolvem mecanismos diversos de vinculação entre processos microscópicos e processos gerais, através de redes de poder que não possuem apenas um, mas vários centros. Assim, Rose procura se desvincular da sobrevalorização do problema do Estado no debate político e na teoria social para repensar o lugar do Estado dentro de uma análise sobre governamentalidade.

As questões sobre governo que interessam ao autor são aquelas relacionadas à regulação do comportamento dos indivíduos em várias e diferentes situações da vida cotidiana. Entende que o comportamento das pessoas em prisões, em clínicas, em salas de aula, em fábricas e escritórios, em aeroportos, nas relações sexuais, e em muitas outras circunstâncias revela a interação entre programas de administração da conduta humana e tecnologias de governo que permitem a sua realização. Nesta perspectiva, a questão do Estado é recolocada. O Estado aqui aparece como um dos vários elementos que compõem circuitos variados de poder,

Latitude, Vol. 1, nํ2, pp.80-98, 2007. 
que colocam em conexão uma diversidade de forças e de autoridades (ROSE, 1999, p. 5). Em outras palavras, o autor desenvolve o postulado foucaultiano da "govermentalização do estado" para abordar o conjunto complexo de estratégias e negociações que envolvem a autoridade estatal nas suas relações com outras autoridades, outras atividades e outros eventos distantes no espaço e no tempo. Neste sentido, o lugar do Estado na execução de estratégias e práticas específicas destinadas ao governo de diferentes problemas não pode ser previamente definido sem uma investigação empírica. Nesta abordagem, portanto, governo não é nem um conceito nem uma teoria, mas algo que deve ser entendido nominalmente, isto é, uma perspectiva. Trata-se de um domínio de questões que precisam ser formuladas e de práticas que precisam ser avaliadas a todo o momento: "se nenhum evento pode falar por si próprio, eles devem sempre ser individualizados e conceitualizados de modo particular" (ib.: 22 e 57). Em uma frase, análises de governo são diagnósticos.

Rose entende que as atividades de governo estão intimamente relacionadas a domínios de saber. Sempre na esteira de Focault, Rose acredita que existe uma correlação mútua entre, por um lado, o modo como certas linguagens de descrição, explicação, cálculos e julgamentos adquirem o valor de verdade e, por outro, as técnicas que são tornadas exeqüíveis graças a essas verdades. O governo de uma população, de uma economia nacional, de uma empresa, de uma família ou mesmo o governo de si próprio, só se torna possível através de mecanismos discursivos que representam o domínio a ser governado como um campo inteligível, com limites e características específicas, e cujas partes componentes estão ligadas umas às outras de uma maneira mais ou menos sistemática. Um exemplo disso está no fato das estratégias inventadas no meio do século XX para o gerenciamento de uma economia nacional tornarem-se possíveis não apenas por causa da implementação de um novo conjunto de conceitos para pensar a economia, mas também por causa da construção de um vasto aparato estatístico através do qual este domínio pôde ser inscrito, visualizado, tabulado, modelado, calculado, comparado, etc. (ib. p. 33). Nesta acepção, portanto, as noções de governo e de governamentalidade demarcam as fronteiras analíticas de um campo de investigações sobre as modernas interrelações entre conhecimento e poder:

"The activity of government is inextricably bound up with activity of thought. It is thus both made possible by and constrained by what can be thought and what cannot be thought at any particular moment in our history. To analyse the history of government, then, requires attention to the conditions under which it becomes possible to consider certain things to be true - and hence to say and do certain things about human beings and their interrelations (...) Of course, there are many different ways in which thought has rendered itself truthful and in which authority has linked itself to truth" (ib. p. 8)

Latitude, Vol. 1, nํ2, pp.80-98, 2007. 
Não se trata aqui de uma questão relacionada à linguagem entendida como um campo de significados, ou ao que convencionalmente entendemos por "contextualização" da produção de textos. As análises de governamentalidade estão muito menos preocupadas com o que significa uma palavra ou um texto. Antes, sua atenção é voltada para a análise dos modos como uma palavra ou um texto funciona em conexão com outras coisas, o que os torna possíveis, suas superfícies, as redes e circuitos que os colocam em fluxo, os afetos e as paixões que eles mobilizam e que são por eles mobilizados (ib. p. 29). Ao invés da usual preocupação hermenêutica voltada para a decodificação e interpretação de estratégias particulares e seus motivos ocultos, a análise procura considerar argumentos, estratégias e táticas em seus próprios termos, isto é, enfatiza-se os processos de identificação que essas estratégias e táticas produzem, os objetivos que elas próprias estabelecem, as linguagens e categorias que utilizam para se auto-descrever (ib. p. 56). Trata-se, portanto, de uma atualização da premissa foucaultiana sobre a ontologia dos discursos, segundo a qual o conhecimento não é uma descrição, mas uma (auto) formação da realidade.

\section{Translação e produção de verdades}

Ao aderir às proposições de Foucault sobre produções de verdades, Rose entende que os discursos possuem regras endógenas de auto-formação. $\mathrm{O}$ autor procura explicar formações discursivas específicas com base apenas em seus próprios acontecimentos. Neste sentido, Rose entende que a governamentalidade como formação discursiva é algo que estabelece suas próprias unidades de análise. As relações entre espaço e território são ilustrativas disso. Argumenta que, tradicionalmente, o problema da territorialização de um governo sempre foi pensado como o problema de demarcação mental de um território e da sua inscrição na realidade, levando-se em conta sempre a referência a espaços nacionais. O tratamento de cidades, bairros, regiões ou mesmo civilizações são exemplos comuns de análises sobre governo que traçam diferentes analogias sobre um mesmo princípio comum: a territorialidade do Estado-nação. Na visão de Rose, a novidade que as análises sobre governamentalidade podem oferecer nesta questão é a possibilidade de redimensionar essas unidades mais convencionais de análise. Propõe estudar o pensamento governamental em espaços diferentes, como nas escolas, fábricas, hospitais, asilos, museus, aeroportos, espaços que não estão diretamente circunscritos às fronteiras nacionais. Fundamental para isso é levar em consideração os critérios de espaço que são criados e recriados pelos governos para o exercício de seu poder. Rose leva adiante esta tarefa na medida em que dialoga a perspectiva foucaultiana com a contribuição de Bruno Latour.

De um modo geral, Latour (1981; 1986 e 1996) tem um especial interesse em estabelecer novas conceitualizações sobre as relações "micro" e "macro" da vida social. Latour se dedica a analisar como um micro ator torna-se um macro ator, isto é, como é possível que vários homens atuem como se fosse um só. Para 
isso, recorre a Hobbes para considerar que entre micro e macro atores não há diferenças intrínsecas com relação ao peso, nível ou escopo de cada um, atribuindo qualidade isomórfica a todos os atores, sejam eles macro ou micro. No entanto, enquanto Hobbes procura resolver esta questão com a noção de contrato social, Latour caminha sobre outras bases. Para Latour, o contrato social é apenas uma instância particular de um fenômeno mais geral, o fenômeno da translação. Entende por translação todas as negociações, intrigas, cálculos, atos de persuasão e violência em que um ator ou uma força adquire autoridade para falar ou agir em nome de outros atores ou forças. Latour acredita que o melhor modo de considerar esta qualidade isomórfica e transitória dos atores é considerá-los como redes. Duas redes podem possuir uma mesma forma, mesmo que uma esteja limitada a um ponto específico e a outra se estenda por muitos outros pontos além desse, do mesmo modo que um soberano pode ser "um entre outros" e ao mesmo tempo a personificação de todos os outros.

Além de correlacionarem várias outras vontades, os macro-atores correlacionam também um grande número de objetos. Para Latour, devemos levar igualmente em consideração o modo como um macro-ator correlaciona em si mesmo não apenas outros corpos e vontades, mas também materiais, discursos, técnicas, sentimentos, leis e organizações. Os objetos estão correlacionados entre si de um modo particular que tende a simplificar a realidade social na medida em que especificam os mecanismos de entrelaçamento entre os vários recursos (materiais e humanos) de construção da vida social. As inúmeras possibilidades de suas combinações condicionam a extensão e amplitude da formação de determinadas redes que podem se sobrepor umas às outras. Tudo o que se refere ao que tradicionalmente é tratado na sociologia como estrutura, Estado, padrão social, teoria, etc, são conseqüências dessas sobreposições. Latour sustenta suas proposições em uma perspectiva linear de análise, segundo a qual, independente da maior ou menos distância em que seja analisado um objeto, será sempre possível operar movimentos de translação dos seus vários níveis. Isso possibilitaria a apresentação de um mesmo objeto em tamanhos diferentes quando visto a partir de diferentes posições, sem que este movimento de transferência altere suas propriedades internas (ib.).

Rose retoma a noção de Latour sobre translação para operar metodologicamente premissas analíticas de inspiração Foucaultiana. A sua análise sobre neoliberalismo é ilustrativa disso. Rose entende que o governo conservador de Margaret Thatcher nos anos 80 não foi o resultado da realização prática de qualquer filosofia. Antes, esta forma de governo resultou da correlação entre pensamento e ação no modo como vários problemas de governo foram sendo resolvidos através de instrumentos e procedimentos que se tornaram disponíveis no próprio acontecimento, isto é, como tentativas práticas de pensar e agir sobre problemas específicos em locais particulares. No curso deste processo, um determinado tipo de racionalidade, então chamado de neoliberalismo, passou a prover um modo específico de relacionar essas várias práticas, integrando-as em uma coerência lógica. Depois de ser extraída ad hoc um tipo de racionalidade nessas técnicas e práticas, tornou-se possível o movimento de translação. Essas

Latitude, Vol. 1, nํ2, pp.80-98, 2007. 
racionalidades passaram a ser corporificadas em toda uma variedade de práticas e pressupostos de regulação da vida econômica, de assistência média, de benefícios profissionais e assim por diante. O neoliberalismo, portanto, não é o resultado de uma ou outra doutrina filosófica que a tenha precedido, mas o resultado contingente de práticas de governo que procuram continuamente se auto aferir uma forma de verdade (ROSE, 1999, p. 27).

Independente da formação discursiva sob a qual está revestido, o governo é sempre exercido através da articulação entre diversos micro-locais, onde autoridades de todos os tipos exercem seus poderes sobre as pessoas. Nos movimentos de translação, determinadas estratégias, cálculos e programas formulados em alguns centros são relacionados a atividades distantes espacial e temporalmente. Rose entende que existe uma negociação constante entre autoridades de governo e as várias outras autoridades que compõem um domínio a ser governado, como, por exemplo, filantropistas, médicos, gerentes, famílias, trabalhadores, etc. A fim de governarem à distância (não apenas espacial e temporal, mas também constitucional), as forças políticas devem instrumentalizar formas de autoridade que são diferentes daquelas do Estado. Para Rose, a translação relaciona o geral ao particular, liga um lugar a outro, modifica modos de pensar, partindo de um centro político para uma infinidade de lugares de trabalho, hospitais, escolas, lares, etc. Assim, programas nacionais de governo vão ajustando e sendo ajustados por uma proliferação de procedimentos técnicos e práticos voltados para a afirmação da "conduta da conduta" em um nível molecular, dissipado por todo o corpo social. (ib. pp.48-50).

\section{Neoliberalismo em suas exceções: a proposta de Aihwa Ong}

Outro trabalho que tem merecido destaque dentro dos estudos de governamentalidade é o de Aihwa Ong. A autora define o neoliberalismo como uma formação discursiva assentada em dois postulados gerais: a reivindicação de que o mercado é melhor do que o Estado na distribuição de recursos públicos, e o retorno a uma forma primitiva de individualismo, um individualismo competitivo, possessivo e geralmente construído nos termos de uma doutrina sobre o consumo, enfatizando-se tanto eficiência econômica quanto responsabilidade ética. Mais do que isso, Ong retoma as contribuições de Foucault e Rose para argumentar que o neoliberalismo traduz um novo tipo de relação entre governo e poder, em que as atividades de governo são reformuladas como problemas não políticos e não ideológicos que demandam soluções técnicas (ONG, 2006a, pp.3 e 11). Sustenta que a noção de neoliberalismo envolve um conjunto móvel de técnicas e cálculos de governo que podem ser descontextualizadas de suas fontes originárias e recontextualizadas em outras regiões. O trabalho da autora consiste no esforço de realizar uma etnografia sobre os alinhamentos mais recentes entre racionalidade de 
mercado, soberania e cidadania em diferentes regiões do mundo. Neste sentido, entende que a formação discursiva do neoliberalismo é um fenômeno geral com efeitos variados em diferentes contextos políticos e culturais (ONG, 2006a e ONG, 2006b).

Ong afirma que o neoliberalismo tem reconfigurado as relações entre governo e governados, entre poder e saber, e entre soberania e territorialidade de modo diferente em diversos contextos. Para compreender os efeitos variados do neoliberalismo em países não ocidentais, a autora faz uso de duas noções chave na sua análise: "neoliberalismo como exceção" e "exceções ao neoliberalismo". A primeira remete ao desenvolvimento de "capitalismos alternativos", que não são alternativas ao capitalismo. As exceções neoliberais são o conjunto de procedimentos políticos neoliberais operados em países onde o neoliberalismo não é a característica predominante das tecnologias de governo. O neoliberalismo como exceção é empregado nos mais variados cenários políticos, como póscolonialismos, autoritarismos e pós-socialismos, cenários em que é observada a introdução de cálculos mercadológicos no gerenciamento de populações e na administração dos espaços. Por sua vez, as exceções ao neoliberalismo representam a exclusão de populações e espaços dos cálculos e escolhas neoliberais. Exceções ao neoliberalismo tanto podem ser modos de proteção social a determinados indivíduos quanto modos de suprimir todas as formas de proteção política. $\mathrm{O}$ objetivo de seu trabalho consiste em analisar a sobreposição entre neoliberalismo como exceção e exceções o neoliberalismo em países do sul e leste asiático ${ }^{3}$. Ong se dedica a explorar as dependências mútuas entre neoliberalismo como exceção e exceções ao neoliberalismo, isto é, procura compreender lógicas mercadológicas de exceção que são realizadas em uma variedade de contextos etnográficos e que acabam por redefinir modelos convencionais de soberania e de cidadania. Para a autora, populações governadas por tecnologias neoliberais são dependentes de outras populações que são excluídas das considerações neoliberais (ONG, 2006a, pp. 3-5).

A tese central defendida pela autora é que a fusão entre neoliberalismo como exceção e exceções ao neoliberalismo modifica concepções tradicionais de soberania e cidadania através da articulação e desarticulação entre a racionalidade neoliberal e seus mecanismos. Ong retoma a contribuição de Foucault sobre governamentalidade, entendendo neoliberalismo como uma tecnologia de governo fundamentada em cálculos e técnicas voltados para a formação dos domínios de soberania e cidadania. Argumenta que a governamentalidade neoliberal resulta da infiltração de verdades e cálculos mercadológicos dentro da esfera política, diversificando seus espaços:

${ }^{3}$ Já na capa de seu livro há uma foto bastante emblemática do argumento. Nela, há imagem de duas mulheres com fenótipos orientais. Uma delas está bem vestida e carrega o que parece ser uma sacola de shopping center em uma mão e um telefone celular na outra. Possui um corpo esbelto e está em movimento. A outra mulher veste roupas muito mais simples, está parada e carrega caixas de cebolas e frutas. Aparenta ser uma vendedora ambulante. Ambas dividem a mesma calçada. 
"I use Foucault's insights on economic rationality in techniques for governing populations in a field of intervention, recasting them in the light of contemporary technologies of governing. Neoliberal reason, I argue, has taken economic rationality in highly flexible direction that does not use the national territory as the overriding frame of reference for political decisions. Rather, the neoliberal stress on economic borderlessness has induced the creation of multiple political spaces and techniques for differentiated governing within the national terrain. Especially in emerging postcolonial contexts, varied techniques of government rely on controlling and regulating populations in relationship to differentiated spaces of governance, with a graduate effect on sovereignty, and on citizenship" (ib., pp.76-77).

Ong procura situar os postulados teóricos desenvolvidos por autores dos estudos de governamentalidade dentro de pesquisas empíricas. Neste sentido, os vários exemplos arrolados em sua argumentação dizem respeito à investigação de como o neoliberalismo, entendido como fenômeno global, é diferencialmente operado em contextos contemporâneos os mais diversos. A fim de entender as alterações mais recentes que o Estado nacional tem experimento ante a intensificação de processos globais, Ong foca atenção especial nas respostas que Estados em desenvolvimento têm oferecido aos desafios de forças globais contemporâneas. A autora procura avaliar de que modo a lógica do neoliberalismo é empregada em uma variedade de contextos etnográficos, diversificando práticas estabelecidas de cidadania e soberania. Ong entende que a noção de neoliberalismo como um modo de "governar através da liberdade" tem se tornado um estilo dominante de políticas de governo tanto nas democracias liberais mais avançadas, quanto em países com pouca tradição democrática. Políticas neoliberais de diminuição do Estado são acompanhadas pela proliferação de técnicas de governo que refazem os temas tradicionais da cidadania, na medida em que requerem que as populações sejam livres, auto-gestoras, isto é, que os indivíduos sejam sujeitos auto-empreendedores em diferentes esferas da vida cotidiana, como saúde, educação, burocracia, profissões e etc. (ib. p. 14).

Se a propagação da racionalidade neoliberal nas relações entre Estado e mercado é um processo geral de alcance mundial, as respostas que as sociedades oferecem a este processo variam em função das singularidades sócio-históricas sobre as quais elas estão imersas. Ong identifica exemplos dessas variações em países asiáticos que combinam autoritarismo político e liberalismo econômico. Entende que, embora esses países não sejam formações neoliberais em um senso estrito, as suas inserções dentro da economia global têm requerido deles a adoção de determinados cálculos neoliberais para manejarem as populações através das quais realizam esta inserção. Na prática, isso significa uma reconfiguração desses territórios nacionais em múltiplas zonas de desenvolvimento, espaços diferencialmente vinculados a redes transnacionais de mercados, tecnologia e 
competência, com desigual concentração de recursos políticos, econômicos e sociais. Essas técnicas reflexivas de engenharia social e de re-engenharia das subjetividades interagem com diversos regimes éticos, cristalizando os problemas contemporâneos de cidadania e ética dessas sociedades. (ib. pp. 78-79).

\section{O desafio de novos métodos e unidades de análise}

Feita esta breve incursão nos trabalhos de Nikolas Rose e Aihwa Ong, vejamos agora, de modo igualmente breve, de que modo eles dialogam entre si na proposição de novos caminhos para a teoria sociológica contemporânea. Em especial, irei agora apenas mencionar como essas duas contribuições neofoucaultianas podem favorecer a elaboração de novos métodos e unidades de análise, diferentes, por exemplo, daqueles consagrados pelo nacionalismo metodológico. O modo particular de construção empírica dos objetos, a noção de tecnologia e a noção de rede são três aspectos que estão correlacionados na formação desse novo campo de investigações sobre a governamentalidade.

Metodologicamente, creio que uma proposição comum nesses estudos diz respeito à construção de um tipo especial de empirismo. Tal como Foucault, Rose e Ong não estão preocupados em formular novas teorias com intenção de generalidade probabilística, nem em testá-las. Antes, estão dedicados a operar um modo de reconstituição histórica que tem por objetivo compreender a emergência de determinados regimes de verdade dentro de redes particulares de poder. Para isso, recorrem a uma metodologia de inspiração deleuziana, em que os conceitos não antecedem os objetos, mas surgem na sua própria construção. Trata-se, pois, de um empiricismo em que os conceitos são criados e recriados na própria configuração dos acontecimentos estudados. Rose, por exemplo, chama isso de diagnósticos. Diagnosticar envolve o trabalho de discriminação, ou diferenciação, isto é, o trabalho de estabelecer as singularidades ou individuações que ocorrem dentro de um conjunto de relações que compõem o objeto estudado (ROSE, 1999, p. 57). O diagnóstico (ou a genealogia) do governo procura compreender as especificidades das estratégias singulares de correlação entre poder e conhecimento. É exatamente isso o que também faz Ong ao se ocupar com as diferentes gradações de soberania e cidadania relacionadas a espaços e populações que estão diferentemente ligados a circuitos globais.

A ênfase que os dois autores atribuem à dimensão tecnológica nas formas de governo é outro ponto em comum importante entre as duas abordagens. Mais do que características eminentemente técnicas, as tecnologias de governo são aquelas imbuídas por aspirações de modulação de condutas e, como tal, estão ligadas à produção de subjetividades. Os sistemas de comunicação e as redes de informação, por exemplo, não são apenas máquinas impostas aos indivíduos, são também desejadas por eles. Neste sentido, não há como pensar identidade e subjetividade sem relacioná-los a fatores políticos e sociais (FOUCAULT, 2003, p. 318). No rastro de Foucault, Rose e Ong reconhecem a natureza simultaneamente 
biológica e política de um novo paradigma sobre poder, a biopolítica. Compreendem biopolítica como uma forma de poder que rege e regulamenta a vida social em seus próprios interstícios, nas suas dimensões mais microscópicas. Nesta perspectiva, o poder não obtém um domínio efetivo sobre a população a menos que se torne uma função integrante e vital que cada indivíduo abraça e reativa por sua própria vontade. Formas de identidade, de subjetividade, de agência e de vontade não são antitéticas ao poder e à técnica. Antes, são partes constitutivas das várias configurações do poder (ROSE, 1999, p. 54 e Ong, 2006a, p. 13).

Estes novos caminhos metodológicos que os autores dos estudos de governamentalidade procuram seguir na operação de uma concepção multifacetada de poder acabam por demandar a proposição de novas unidades para análise. O espaço nacional, que tradicionalmente serviu ao propósito de pensar concepções mais uniformes e unilaterais das relações de poder, não tem validade heurística nestas novas abordagens. Ao invés de pensar as relações de poder em espaços invariáveis, Rose e Ong fazem referência constante às formações dos mais variados tipos de "redes" por onde se dispersa o poder. Neste sentido, aproximam-se também de abordagem de Manuel Castells (1996), para quem as redes constituem a nova morfologia das nossas sociedades. Tal como Castells, Rose e Ong compreendem redes como um conjunto de vários "nós" interconectados, formando estruturas abertas e destituídas de um único centro gravitacional de poder. A difusão da lógica de redes nas sociedades contemporâneas modifica de forma substancial a operação e os resultados de processos relativos ao poder.

No geral, além das racionalidades políticas (isto é, do campo discursivo dentro do qual o poder é conceitualizado), as análises de governamentalidade focam também atenção nas tecnologias de governo (isto é, no conjunto complexo de programas, cálculos, técnicas, documentos, etc.) através dos quais as autoridades procuram corporificar e exercer suas ambições governamentais. A interdependência entre as racionalidades políticas e as tecnologias de governo torna possível aos autores descrever as múltiplas conexões entre redes, que colocam a vida dos indivíduos, grupos e organizações em conexão com os objetivos das autoridades, inaugurando novos espaços de disputa e de reconhecimento político (ROSE e MILLER, 1992; ONG, 2006b). Os pontos centrais que estão sendo levados adiante neste novo campo de investigações dizem respeito aos processos de subjetivação do poder em suas relações microscópicas e descentradas.

\section{Considerações finais}

De modo geral, os estudos de governamentalidade estão situados dentro das novas agendas que estão sendo formuladas nas ciências sociais contemporâneas. De fato, além destas abordagens, há muitas outras teorias que estão dispostas a repensar conceitos e metodologias mais convencionais nas 
ciências sociais. A intensificação de processos globais tem trazido uma série de impasses para as reflexões tradicionais da sociologia e são muitas as respostas que os sociólogos têm oferecido a estes impasses. As assim chamadas "teorias de síntese" talvez sejam o reflexo mais imediato desta nova fase da disciplina. Dentre outros, autores como Pierre Bourdieu (2003) e Anthony Giddens (1996) têm recebido grande atenção devido ao esforço que realizaram para ajustar premissas do objetivismo e do subjetivismo em seus modelos de análise. No entanto, a proposta de síntese ainda não parece ter sido bem resolvida na sociologia. Se, por um lado, esses modelos de análise obtêm relativo sucesso ao contemplar tanto as coerções das estruturas quanto a agência dos indivíduos, por outro lado, suas formulações lógica e teórica estão, em última instância, ancoradas por um ponto de partida estabelecido desde dentro da dicotomia entre estrutura e agência. Isso fica claro na medida em que comparamos as propostas de síntese de Bourdieu (quem, em última instância, favorece a reprodução) e de Giddens (quem, em última instância, favorece a criação). Esses autores não desconstroem a dicotomia entre micro e macro na análise sociológica, apenas a colocam em novas bases. Menos do que uma síntese, o que essas análises acabam por propor é um ajuntamento.

Além das teorias de síntese, um outro modo de pensar alternativas teóricas e metodológicas para a proposição de novas unidades de análise nas ciências sociais é apresentado pela tradição pós-estruturalista em suas mais variadas vertentes, como no caso dos estudos de governamentalidade. Com base no que foi exposto nas seções precedentes, podemos inicialmente concluir que o conceito de rede e o descentramento da noção de poder estabelecem com sucesso a proposição de unidades de análise que estão fora da dicotomia entre dimensões macro e micro da vida social. No entanto, essas novas unidades de análise são formuladas sem intenção de propor um conhecimento teórico geral e probabilístico. Autores como Foucault, Latour, Rose e Ong rechaçam qualquer possibilidade de constituir uma teoria geral sobre os processos que estão analisando.

Por um lado, os estudos de governamentalidade avançam na intenção de fundar um campo de investigação sobre a produção de verdades em suas relações de poder, por outro, não há razão para acreditar que isso só seja possível mediante o abandono de qualquer pretensão à generalização teórica. A exemplo de Norbert Elias (1993), Reinhard Bendix (1996), Charles Tilly (1996) e muitos outros sociólogos, podemos crer que há sim possibilidade de tratar as singularidades históricas através da generalidade teórica, sem com isso abandonarmos uma perspectiva crítica sobre o que é estudado. Entendo que o estabelecimento de um pensamento crítico no tipo de produção de conhecimento gerado pela sociologia não pode ficar refém da renúncia à elaboração de proposições gerais e probabilísticas. Não há dúvidas de que o adensamento, a complexificação e o alargamento das redes de interdependência mútua entre os indivíduos são sinais de novos tempos e exigem da sociologia um redimensionamento das suas bases epistemológicas, a fim de que ela dê conta dessas alterações. De fato, não há como prosseguir acriticamente com os mesmos modelos conceituais que consagraram a disciplina na esteira das teorias da modernização. No entanto, não acredito que o caminho para isso seja o abandono da pretensão generalizante da teoria 
sociológica, mas sim a proposição de novas teorias. Creio que submeter o tipo de reflexão proposta pelos estudos de governamentalidade à formulação de enunciados gerais é algo que pode contribuir para que sociologia torne mais sólido o terreno movediço em que por hora ela se encontra.

\section{Bibliografia}

BECK, Ulrich. What Is Globalization? Cambridge: Polity Press, 2000.

BENDIX, Reinhard. Construção Nacional e Cidadania. São Paulo: Edusp, 1996.

BOURDIEU, Pierre. O Poder simbólico. Rio de Janeiro: Bertrand Brasil, 2003.

CASTELLS, Manuel. The Rise of the Network Society. Oxford: Blackwell, 1996.

CHERNILO, Daniel. Social Theory's Methodological Nationalism Myth and Reality. European Journal of Social Theory, 9(1): 5-22, 2006.

ELIAS, Norbert. O Processo Civilizador. Rio de janeiro: Zahar, Vol.2, 1993.

FOUCAULT, Michel (2003). Ditos e escritos. Rio de janeiro: Forense Universitária, Vol.4, 2003. . A Arqueologia do Saber. Rio de Janeiro: Forense Universitária, 2000. . Vigiar e Punir: nascimento da prisão. Petrópolis: Vozes, 1987. . A Verdade e as Formas Jurídicas. Rio de Janeiro: NAU, 1996.

GIDDENS, Anthony. As Novas Regras do Método Sociológico. Lisboa: Martins Fontes, 1996.

LATOUR, Bruno. CALLON, Michel. Unscrewing the big leviathan: how macrostructure reality and how sociologists help them to do so. In: KNORRCETINA, K. CICOUREL, A. V. (Eds). Advances in Social Theory and Methodology. London: Routledge, 1981.

LATOUR, Bruno. On Interobjectivity. Mind, Culture and Activity. Vol.3, no․4, 1996.

Drawing things together. In: LYNCH, Michael. WOOGLAR, Steve. (Eds.). Representations in Scientific Practice. London: The MIT Press, 1988.

ONG, Aihwa. Neoliberalism as Exception: mutations in citizenship and sovereignty. London: Duke, 2006.

Mutations in Citizenship. Theory, Culture and Society. Vol. 23, pp. 499531. London: Sage, 2006.

REIS, Elisa. Processos e Escolhas. Rio de Janeiro: ContraCapa, 1998

ROSE, Nikolas; MILLER, Peter. Political Power Beyond the State: problematics of government. British Journal of Sociology. V.43, n‥2, 1992.

Latitude, Vol. 1, nํ2, pp.80-98, 2007. 
ROSE, Nikolas. Powers of Freedom: reframing political thought. Cambridge University Press, 1999.

SMITH, Anthony D. The Nation in History: historiographical debates about ethnicityand nationalism. Hanover: University Press of New England, 2000.

TILLY, Charles. Coerção, Capital e Estados Europeus. São Paulo: Edusp, 1996.

TOURAINE, Alain. Le retour de l'acteur. Paris: Fayard, 1984.

Latitude, Vol. 1, nํ2, pp.80-98, 2007. 